Apart from these terrible risks, we must surely be excused if we fail to be able to contemplate with equanimity the idea of the horrible pain which such a blow must cause at the time. Surely, Sir, there is no need for ladies to indulge in this eminently virile game. There is no doubt of their muscular capacity, but the areater this is, the greater the risk of injury in this particular game. We have tennis and other games, which, compared with cricket, are harmless; cannot the ladies be persuaded to content themselves with these? I am, Sirs, yours truly,

Finshury-circus. W. Henry Kesteven.

\section{MR. SPEAR'S REPORT ON DIPHTHERIA AND CROUP IN THE SUB-DISTRICT OF PONTYPRIDD. \\ To the Editors of THE LANCET.}

SIRs,-In your issue of June 7th you give some extracts from the above report. As I was the medical attendant of all the cases of diphtheria and croup in the Cilfynydd district would you kindly allow me to refer to one statement in the report? On p. 3 I find that " no precautions whatever were taken or attempted to be taken to prevent its extension" Soon after I came to Pontypridd (in Noy. 1887), I noticed the great prevalence of throat affections in the district of Cilfynydd. As I was confident they were due to the insanitary condition of the village, I brought the matter several times to the notice of what I thought was the proper anthority, but nothing was done. During the year 1888, both by letter and personally, I communicated several times with the inspector of nuisances, and even took him over the plague spots of the place myself with the view of having some improvements effected. Towards the end of that year diphtheria was very prevalent, and I persistently kept the insanitary condition of the place before those interested. Owing to my action a public meeting was held in the village which I attended, and it was at that meeting the deputation mentioned on p. 3 (of which I was a member) was appointed to wait on the sanitary authority. Another meeting was subsequently held, and I went with a deputation to the ground landlords, and in the most earnest way pointed out the terrible condition of the place and besought immediate action. I also communicated several times with the agent of some of the property where the drainage was defective, and I am justified in saying that it was owing to my representations that a new drain was laid down in this street and other drains elsewhere, as well as having the village daily scavenged. I stated these facts to Mr. Spear, and remember adding that " not being the medical officer of health, I did not see that I could do more." As to preventing the spread of the disease by personal contagion (granting that it is communicated in that way) it was simply impossible. As the report states: "The practice of taking lodgers is general, and there is considerable overcrowding"; and on p. 8: "As the medical officer of health [of the Pontypridd urban sanitary district] points out, isolation in the cottages of the district is practically impossible." Time after time have I endeavoured to prevent the visits of sympathising friends and neighbours, often accompanied by children; but very often my warning was unheeded. Since Mr. Spear's investigation another child has died of diph theria, and there were two cases of "diphtheritic" throat in the same house; but the disease did not spread further. For a long time the district was totally neglected by the sanitary authority, and even now they have declined to adopt the Notification of Diseases Act.

June 23rd, 1890 I am, Sirs, yours respectfully,

J. ShaW LytTLE, M.D.

\section{THE CHEMISTRY OF GOUT.}

To the Editors of THE LANCET.

Surs, - I appeal to the apothegm that stands at the head of your correspondence colunn, "Audi alteram partem," in asking you to do me the simple justice of allowing me to say that the liypothesis submitted by Sir William Roberts in his recent paper on the Chemistry of Gout, affords a clear and probably accurate exposition of the rationale of "the iodine treatment," for which I have been so severely held responsible. My contention has been, and still is, that the administration of alkalies, whether as carbonates, citrates, or salicylates of sodium, is not, justifiable, on chenical ground, except in very special states of the system, and then not for its elimination of uric acid; because by giving sodium or any similar base we are facilitating the formation of those very salts which in the main constitute the "irritant" of gout. I have given iodine because $I$ believe and think I can demonstrate that it decomposes the urates, bringing away the sodium base as iodide of sodium, and leaving the uric acid free or in a condition which is unirritating. It now appears, according to the theory propounded by Sir William Roberts, that while the uric acid is in combination as a quadrurate there is no precipitation, but that the moment a biurate is formed down it falls. This is precisely what might be hypothecated from the clinical and chemical study of cases treated with iodine. When the blood becomes saturated, or, perhaps I ought to say, strongly impregnated with iodine, a copious outpouring of uric acid generally occurs, the iodine passing out in the urine as iodide of sodium. If iodide of sodium be administered, the result is much less satisfactory than when the iodine is given in some form which admits of its prompt liberation without the supply of more sodium to facilitate the formation of biurates! I, therefore, sive iodine either as tincture of iodine, or iodoform, di-iodo-hydriodide of caffeine, or hydriodic acid It matters little how it be given if only there be no sodium or similar base given with it. The notion of making elimination easier by rendering the blood increasingly alkaline is not one which will stand the test of scientific criticism, or, as I believe, of bedside practice. The gastric, hepatic, duodenal, and splenic disturbances, which are relieved by "alkaline flushes," with consequent subsidence of the neuralgic symptoms to which they give rise, are not, I venture to think, caused by uric-acid storms, but by alcoholic, lactic, butyric, and hydrolytic fermentations, which are often associated with, and may induce, " uric-acid storms," but are not themselves originated by the behaviour of $\mathrm{C}_{5} \mathrm{H}_{4} \mathrm{~N}_{4} \mathrm{O}_{3}$, or of its immediate combinations. The mere fact of finding an increased quantity of uric acid in the urine after a particular process of digestion, disassimilation, or medical treatment, does not prove that the total quantity of uric acid formed immediately before or at the time of kidney excretion was increased. On the contrary, it not uncommonly happens that accumulations of urates are thrown out by the stimulating action of ingesta which are chemically incapable of either pro. moting, or themselves contributing to, the formation of uric acid. The chemistry of the urates is, indeed, mysterious, but much of the mystery might, I venture to think, be dis. pelled by closer clinical study, with a wholesome disregard of traditional beliefs and prejudices.

I am, Sirs, yours faithfully,

J. Mortimer Granvilite

Hanover-square, W., June 14th, 1890

\section{THE MEDICAL STAFF OF THE ARMY.} To the Editors of THE LANCET.

SIRS, - While thanking you for your article on the Medical Staff and Mr. Stanhope's position, published in the last number of THE LANCET, permit me to say that the vast majority of the department only desire " real army substan. tive rank" (and not sham rank, as Surgeon Parke putit) to enable them to perform their duties in an efficient manner. The question of titles is more in dispute, but if real army rank be given, and the medical staff be created "a Royal corps," compound titles ought to be quite sufficient. The necessity for "rank" is extreme. Let me quote an instance. Quite lately, a surgeon-major in charge of one of the most important station hospitals in India was invited by the general officer commanding the district to dinner. The surgeonmajor was senior to every field officer at the table, yet he was placed below all the majors and given the precedence of a captain. The only excuse for the general is he had only lately taken over command, and possibly he and his A.D.C. knew no better; yet had the surgeon-major belonged to a Royal corps and held substantive rank, such a mistake would be quite imposaible. Only last evening I was visiting the Military Exhibition, and, when looking at the admirable groups representing medical aid to the wounded in the field, I chanced to stand near a group of ladies and gentlemen. The ladies naturally expressed their sympathy with the wounded, but one of the gentlemen exclaimed, "Well, such a scene forcibly reminds 1 s of the courage that 